\title{
Informal Science Pedagogical Innovation to Promote Understanding of Technology Application in Fluids Mechanics
}

\author{
https://doi.org/10.3991/ijet.v16i18.25083
}

\author{
Nor Farahwahidah Abd Rahman ${ }^{\bowtie}$, Anis Nadirah Roslan, Alya Nazirah Azaha, \\ Nadhratul Hidaayah Ismail, Mazlena Murshed \\ Universiti Teknologi Malaysia, Johor, Malaysia \\ nfwahidah@utm.my
}

\begin{abstract}
This study attempts to support the preparation, setup and implementation of innovation for informal science learning that help students with technology application in physics topic. There are 349 students were selected as the sample of this study, in two STEM activities during International Scout STEM Camporee. Following the module developed for informal learning activity, the data collection focus using a survey focus on the learning opportunities created by the module for technology application. Teaching technology application in formal setting is known challenging due to syllabus constraints. Here, fluid mechanics is a branch of physics knowledge that relates directly with the technology application. The innovation in the informal science learning module has a specific focus on the technology application of fluid mechanic. Post and pre-test were conducted. The post-test was conducted to investigate prior understanding of fundamental fluid mechanic concepts during the designing stage with the students' ability to make inference. Descriptive analysis and Pearson correlation were used as the data analysis methods. The finding shows that most of the students did have an initial idea of science concepts such as buoyancy, density, weight of mini Titanic, and Archimedes' principle. However, their ability to make inference and observation is weakly correlated and not significant. This findings show that students are capable to produce observations and inferences when technology application is brought into discussion during informal science learning. As a conclusion, for informal science learning, it is important for educators to consider the outcomes for students' learning because the opportunities for students to tap into their prior knowledge from self-determination can be easily achieved within this setting. This study proposes important measures during informal science learning environment to maximize the learning opportunities.
\end{abstract}

Keywords - informal science learning, innovation in teaching, teaching with technology 


\section{$1 \quad$ Introduction}

Informal science learning is a learning related to science concepts outside formal curriculum content. It can be acquired through various activities such as cocurriculum, watching science programs, museum and science center's visits and outdoors activities. [1] stated that the meaning of outside school context is "learning that is self-motivated, voluntary, guided by the learner's needs and interests, learning that is engaging throughout his or her life". Informal learning designs experiences for learners of all ages, across variety of social setting and cultures [2]. The objective focuses at driving learners' curiosity based on their prior knowledge, observation and assumptions. [27] further supported that science activities must lead student to envision real world phenomenon and unpacked the connection between concepts and application. Thus, resources [29] for learning is equally important for informal science learning although learning happen outside the classroom setting. [29] mentioned about cognitive engagement during informal learning to drive students motivation to become efficient learner.

There is no clear agreement from literatures on the nature of activities that can be defined as informal science learning. Some studies have recognized informal as complementing and extending the learning opportunities for the students beyond those provided in the school [3]. The debates however recognize one distinctive feature between formal learning and informal learning which is the learner's participatory. Learning is said to be informal when the leaners learn voluntarily and self-directing.

There are many benefits that can be gained through the informal science learning such as improving the students' perception on STEM subjects [4], increase students' interest in STEM field [5], help the students to understand the concepts and ability to recall information, [6] develop deeper understanding from meaningful context [7] [8], increase the students' motivation [9] [10] and develop critical thinking [8]. This is recognized because informal science learning uses the concept of "open-ended problem" in daily life. These learning experiences provide the opportunities for students to engage and learn about science [11], by students having control of their own understanding.

However, despite of its potential, there are several challenges in developing deeper understanding of science concepts and practices when conducting informal science activities. One of the challenges is the short period of learning time provided in a specific activity [12]. Thus, the learning is often associated with activities of memorization rather than a sequence of learning. With the movement towards integrated STEM other than just science, students' affordance to participate with knowledge outside the curriculum context is essential. Meanwhile, it may be simplified for educators to view informal science learning as the window of opportunity for better engagement in STEM. The conceptual understanding can be developed when the students are able to make the connection of educational concepts with the existing knowledge. Some research like [28] seen this as combination between formal and informal learning to accommodate students' personalize learning environment. Hence, it is important to investigate whether the students can obtain conceptual understanding of the science concept from the informal science learning. In this article, 
Paper-Informal Science Pedagogical Innovation to Promote Understanding of Technology...

we study learning opportunities during informal science learning among students that come from different educational background.

\section{$2 \quad$ Literature Review}

\subsection{Technology Application in Physics}

The informal science learning has been agreed to provide rich and substantial learning experience for cognitive and affective development [13]. However, most of the studies focus on the affective development which are the students' perception, motivation and interest in learning. Momentary feeling of excitement, satisfaction and motivation during informal science learning somehow do not help students to make an informed decision for their own understanding.

[13] [14] discovered about students' perception of learning STEM after participated in an informal science learning. The study employed phenomenological approach to engage with the 'lived experience' to understand perception about learning STEM, the most challenging part and how the informal learning influence their STEM class in formal setting. The findings of this study have shown that informal learning helps students to understand the reason why they learn STEM subjects in schools. It also provides more context for the subjects that students learn in school. The students also realized that the informal learning activities can help them to excel the subject in schools. This study has shown a positive impact of informal science learning on students' perception. However, the students' perception is not enough to determine the students' understanding on the concept of science through the informal activities conducted.

According to [15], students knew that science activities is fun compared to learning science in class. The separation explains that students adopt the idea of learning science by doing while remaining their actions and values showing that science is formal. There were only few of studies investigated on the students' understanding during informal science learning. In another study, [16] investigated the development of conceptual understanding from a four-day soundscape summer camp. The camp provided an informal science learning. The data was collected through a post-interview, pre-post questionnaire, pre-post drawing activity and field observations. The findings show that the combination of STEM content with application of a specific pedagogical technique resulted to a positive cognitive impact. The participants were able to develop their understanding from direct experience with nature, the access to authentic technology and activities promoting collaborative teamwork.

Next, a study on the $21^{\text {st }}$ century skills development through the STEM high schools were conducted by [18]. The purpose of this study is to analyze the lesson plan and work of the students from the inclusive STEM high schools. It was done to understand the engagement and development of $21^{\text {st }}$ century skills by the teachers. The study observed the practice of $21^{\text {st }}$ century skills; construction of knowledge, solving real-world problems, communication skills, students' collaboration, information utilization, communication technology for learning, and self-regulation. The 
rubric used to analyze the lesson plan is the $21^{\text {st }}$ century learning design (21CLD) learning activity rubric. [15] argues that activity must not be employed only as a way for controlling students' behavior, but also to focus at students' outcome.

Another study focuses on an instructional framework using activity-based learning. The framework was used to provide a meaningful learning in organic chemistry [17]. The instructional framework was developed based on the activity theory [17] to ensure the alignment and coherence between the activities, content of the learning and tools used in the learning environment. This framework is also important to make sure the elements in the theory of the activities are perfectly aligned (goals, tools, concepts and theories). The study seen the methodological obstacle in informal science learning is due to instructional framework. An innovative instructional framework for informal science learning is needed with interactive exhibit which the technology can offer outside of the classroom setting. Augmented reality for instance has also been embraced by museum for informal science learning. Although not all informal science learning can afford to have augmented reality, but, it is possible to adopt the interactivity into the informal science activity. Crucial questions regarding technology application for physics learning embedded in how activity is being presented to the students. Developing a values of physics application must not alienated students from experiencing the technology interactive features itself.

From the previous studies, many of the informal science learning aim to offset students' anxiety with formal learning by providing joyful activities. However, avoiding content during activities may limit the opportunity for learning. Therefore, in this study, rather than focusing at students' acceptance towards the informal learning setting, it explores learning opportunity concept as proposed by [15]. Hence, this paper discusses on:

1. How to synergise between designing in informal activity and formal content during informal learning setting?

2. In what way students are able to create a link between their prior knowledge and ability for making an inference during informal learning setting?

\section{Methods}

The research design of this study is explanatory study [19]. This design was adapted to obtain insights on learning opportunities that occur during the implemented informal science learning. The sample of this study were secondary school students which participated in the Scout STEM Camporee held in Johor Bahru for two days. Two instruments were developed for this study which are a Mini Titanic module and a survey.

A mini Titanic module was developed using ADDIE model which consist of analysis, designing, development, implementation and evaluation stages. Based on the previous studies, during the designing and development stages, a specific pedagogy as recommended by [15] was adopted for teachers to choose specific instructional strategy. In this case, we employed inquiry-based learning and designed the activity with open inquiry. The module allows the students to determine content knowledge that 
they want to focus on. The module sequence consist of five stages following recommendation from [26]:

1. Focusing stage: In this stage, the design focus on diagnostic evaluation on students' prior knowledge. Since the students come from different level of education, thereby, it is necessary for the team to recognize their resource for learning. Students are require to go through reflection by determining (a) what existing knowledge they have? (b) How to use this knowledge? (c) And why we decide on this?

2. Exploration stage: In this stage students will be given the opportunity to deconstruct and construct technology application following the consensus tentative prior knowledge obtained during focusing stage. Students will be given the apparatus needed for them to exercise their knowledge by identifying the technology application that may fit to their own understanding.

3. Reporting stage: Students must now be able to determine their plan of action on how the knowledge can now be translated into technology application.

4. Formalisation \& Application stage: The reconstruction of ideas begin which students now must execute the prototype and test the prototype following their tentative idea

The pre and posttest data collection were administered as in Figure 1. During pretest, the students' prior knowledge were tested based on the concept of buoyancy, density, weight, and Archimedes principle. At the designing stage, which is to develop the mini Titanic, [20] [21] the students were given an instruction (refer to Figure 2) and some materials such as paper cups of different sizes, plastic cups of different sizes, zip-lock bags, popsicle sticks, plastic spoons, straws, cello tapes, a small pool, plastic bottles, scissors and A4 papers. Using the materials provided, the students were required to build their own inference and investigation method for the mini Titanic in 20 minutes according to their initial assumptions (prior knowledge). Next, the mini Titanic was tested for buoyancy while withstanding a $400 \mathrm{~g}$ load.

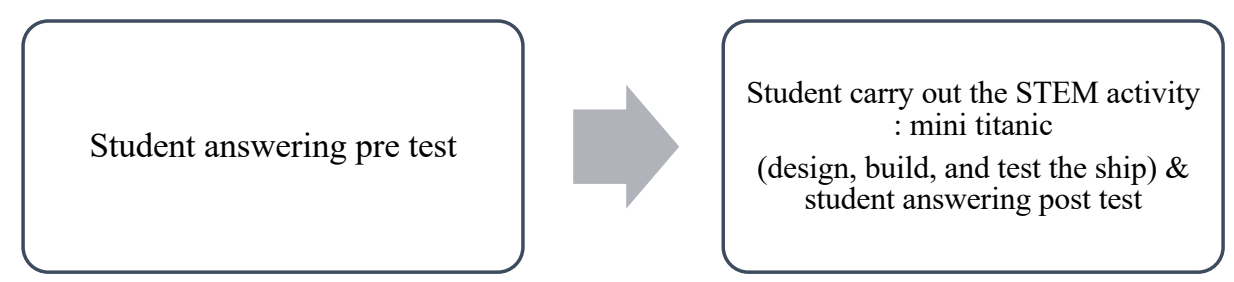

Fig. 1. The flowchart of the STEM activity 


\section{BUILD YOUR OWN MINI TITANIC}

Instruction:

Today, your challenge is to build a mini titanic using your own design with the given materials. Make sure your mini titanic can float in the water. There will be an evaluation to make sure how many loads it can withstand. The more load it can resist, the better it is. You are given 20 minutes to complete this activity. Good luck!

Fig. 2. Instructions for the activity

Any mini Titanic that can withstand the load will get a pass note (refer to Figure 3). During the activity, the students were given post-test to test inference they have made based on their prior knowledge. The activity must be completed in 30 minutes facilitated by the facilitators. A short survey was distributed before and after the activity to provide explanation on students' conceptual development. The survey consists of 1 question for pre-test and 4 questions for post-test. For the pre-post, a question was asked to identify their prior concept of Archimedes' principle.

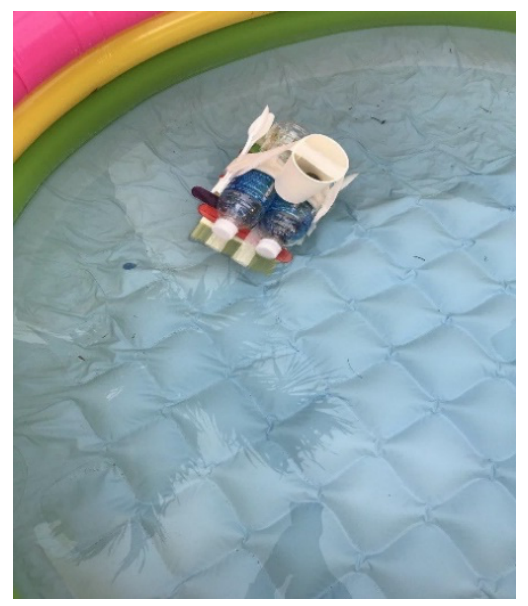

Fig. 3. Example of mini titanic built during by participants

The post-test are based on Archimedes' principle, the elements considered in building the mini Titanic, the conclusion on the principle based on the activity and the design of the mini Titanic. The first question is the same for both pre-test and posttest. The choices of answer for question 1 consist of heat, buoyancy, water pressure, level of water, density of water, volume of water, weight of the mini Titanic, Archimedes' principle and Bernoulli's principle. For question 2, the choices of answer are shape of material, type of material, mass of material, surface area of the mini Titanic, and stability. The third question tests on the skill of making a conclusion based on the principles earlier. The last question for the post-test is to sketch on the design of the mini Titanic. The frequency of the answer by each group was calculated. 
For the post-questions, there were four questions which were designed to identify the reconstruction of knowledge application using Archimedes' principle after completing the activity. From the questions, the data was analyzed using descriptive analysis. The findings of the data were categorized into three levels which are low, medium and high. In addition, the correlation test analysis was also conducted because question 1 and question 3 are related to each other. For question 2, it has two parts which include multiple choices questions and open-ended questions. For the multiplechoice questions, the data was analyzed using descriptive analysis by determining the frequency and percentage of the chosen answers for each choice of answers. From the data, the conceptual understanding among students were interpreted and discussed in detail.

The researchers in this study played their role as the facilitators during the STEM activity. The facilitators focused at making sure the learning can be carried out smoothly without any problems, prompting questions that drive students' curiosity and providing assistance during the each stage. These roles carried out by the facilitators are based on the recommendation by [13]. In this study, the facilitators helped to build the environment of informal learning for the participants as it is important to increase the participants' interest and engagement in the STEM activity [13].

\section{$4 \quad$ Findings}

From the findings in the bar chart in Figure 4, 113 out of 115 groups with $98.3 \%$ from the sample chose buoyancy concept as the answer. Followed by the fifth answer in which 89 of the groups identified that the density of the water is one of the concepts related from this activity. Next, $11.4 \%$ of the groups chose the density of water, $69.6 \%$ of the groups chose the weight of the mini Titanic, and $26.1 \%$ of the groups chose the Archimedes' principle. Eighty groups identified the weight of their mini Titanic is related to this activity and only thirty groups identified the Archimedes' principle. However, there were also wrong concepts chosen by the students which are the concept of heat (1 group), water pressure (48 groups), level of water (22 groups), volume of water (19 groups) and Bernoulli's principle (3 groups=2.61\%). The example is illustrated in Figure 5.

With this question in mind, it is important for students to test their inference by building up the boat using the materials (paper cups of different sizes, plastic cups of different sizes, zip-lock bags, popsicle sticks, plastic spoons, straws, cello tapes, a small pool, plastic bottles, scissors and A4 papers). Students were required to draw their design (refer to Figure 5.) and develop the boat. After completing this activity, they were required to bring the boat for evaluation, to measure its ability to withstand load. While completing this assessment, there were given the second set of the survey for the post-test.

The first stage of analysis for post-test compared the findings from question 1 and 3. Question 1 identified the level of conceptual understanding of science, while question 3 identified the level of ability to make inference. In both questions, which consist of eight choices of answers, four answers are correct, and four answers are wrong. 
Numbers of correct answer were accumulated and ranked according to the level of understanding in Table 1. The level of understanding was categorized into three levels which are low, medium and high, each with different scores.

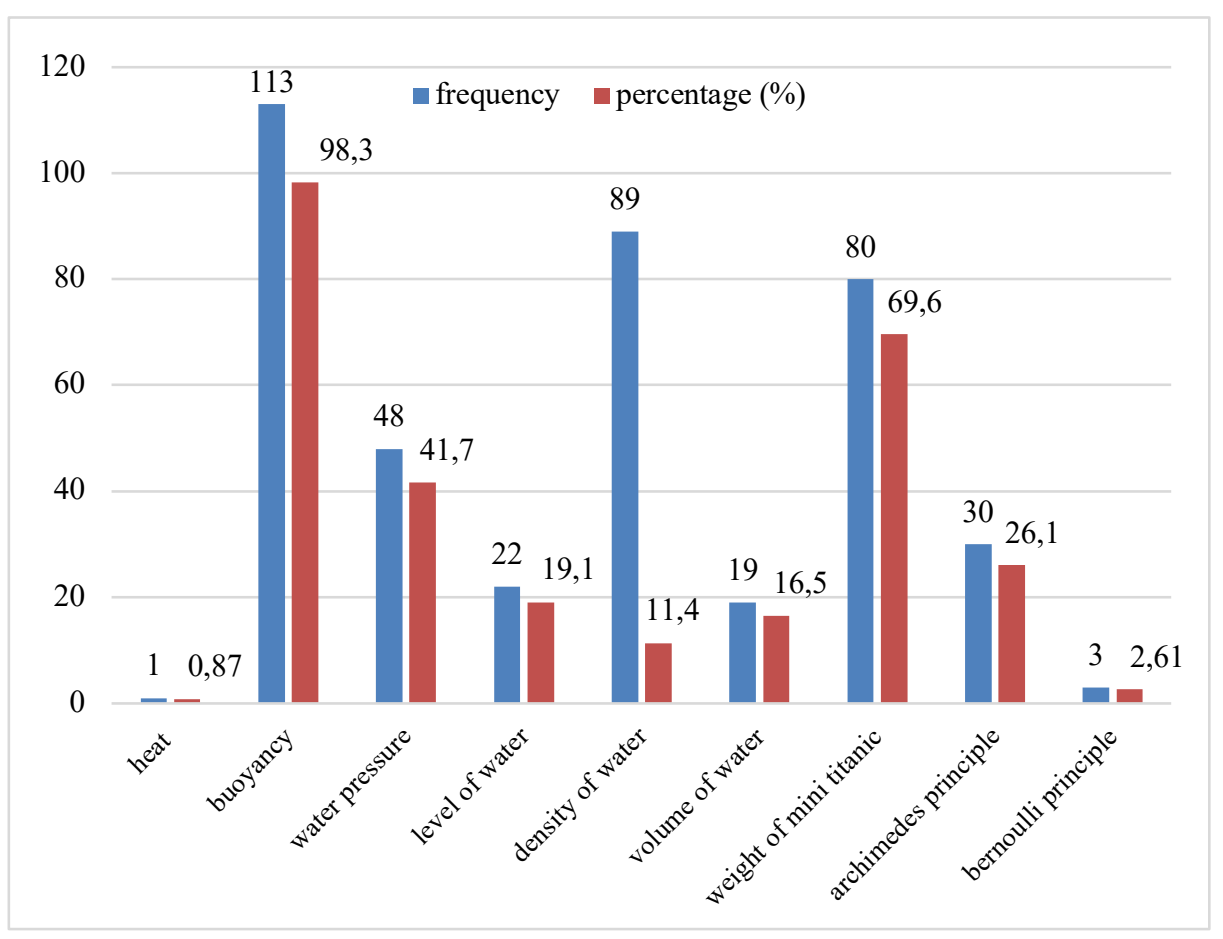

Fig. 4. Bar chart for frequency and percentage of choosing answer for question 1

Table 1. Scoring for post-test survey

\begin{tabular}{|l|c|}
\hline \multicolumn{1}{|c|}{ Level of Understanding } & Number of Right Answer - Number of Wrong Answer \\
\hline Low & 0 and below \\
\hline Medium & 1 and 2 \\
\hline High & 3 and 4 \\
\hline
\end{tabular}

From Table 2, it can be concluded that, most of the group of students scored within moderate level of science concept and moderate level of ability in making inference. Table 1 shows that despite of difference in education background, which most of them have never been exposed with the concept of fluid mechanics, students generally were able to make one to two prior understanding (observation) and assumptions (inference). To understand the students' ability to see the link between their observation and inference, Pearson correlation analysis was conducted as shown in Table 3. The analysis shows weak and insignificant correlation between these two constructs. This imply that, although there was an opportunity created during informal science learning to link the observation and inference, students were unlikely to make relation between observation and making inference. The informal setting are inviting more 
discourse on descriptive statements about the phenomenon. When developing an inference, it was done based on guesses. The confusion can be described as unable to differentiate the role of observation and inference during knowledge construction.

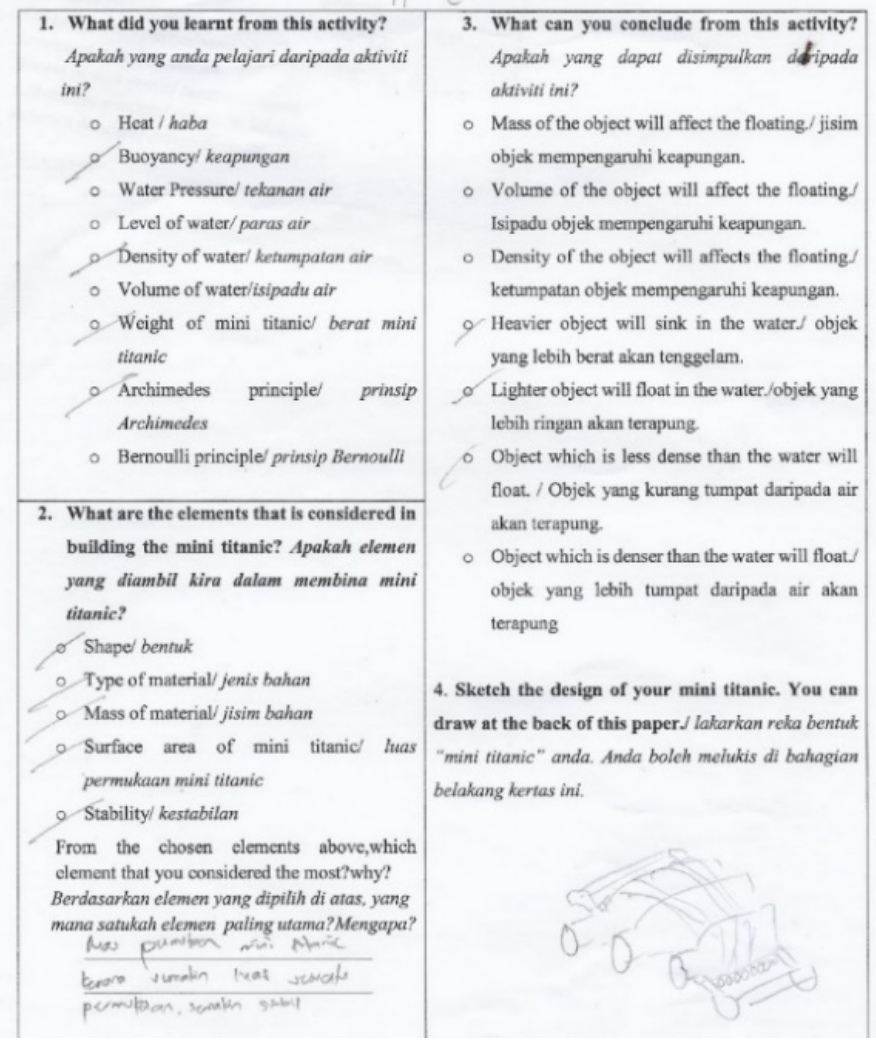

Fig. 5. Example of high level answers in determining the science concept but low level for inferencing and design of the mini Titanic

Table 2. Results level of understanding of group according to the question 1 and 3

\begin{tabular}{|l|c|c|}
\hline \multicolumn{1}{|c|}{ Level of Understanding } & Question 1 & Question 3 \\
\hline Low & 8 & 37 \\
\hline Moderate & 63 & 62 \\
\hline High & 44 & 16 \\
\hline
\end{tabular}

Table 3. Correlation analysis between the level understanding conception of science and ability to make inference

\begin{tabular}{|c|l|c|c|}
\hline \multicolumn{2}{|c|}{} & Concept & Inference \\
\hline \multirow{3}{*}{ Observation } & Pearson Correlation & 1 & 0.011 \\
\cline { 2 - 4 } & Sig. (2-tailed) & & $0.908^{*}$ \\
\cline { 2 - 4 } & $\mathrm{N}$ & 115 & 115 \\
\hline
\end{tabular}




\section{Discussion}

The sample involved in this study are 14 years old secondary students with the experience of learning fundamental Physics concepts such as buoyancy, density and weight from science classes. This explains why majority of them chosen buoyancy concept. It proves that most of the students know that buoyancy concept is related to the activity during focusing stage. The other related concepts such as density of water, weight of the mini Titanic and Archimedes' principle are also among the most chosen concept. Some of the incorrect concepts chose by the students was water pressure. Although water pressure concept is not correlated with the activities, students must have a reason for their choice which shows an indicator for misconception.

The level of understanding of the science concepts in the activity for most of the students are moderate with majority of them getting one or two correct interpretations of the phenomenon. In a formal setting education, students received affirmation from teachers and deliver all the correct answers before testing their assumptions. Instead, during this activity, emancipation appears as the determining factors among students to act on their knowledge and test inferences. This explains why for question 3, majority of the students were able to deliver one or two inferences despite of being uncertain. The design of the module create a condition that able the students to include technology consideration for the concepts. Since the learning environment during informal science learning does not include 'affirmation' from teachers, the module managed to inculcate students' ownership towards knowledge development. Thereby, the nature of knowing surface during informal science learning creates opportunity for emancipation to regulate prior knowledge.

Although the Pearson correlation analysis shows that there is no correlation between the observation and the ability in making an inference, it is an important finding to highlight. From the findings, it shows that the students knew the concepts in the activity but were wrong in making the inference. This is often seen as caused by the misconceptions in Physics knowledge [2] [22]. An example of the misconceptions are the factors that influence the sinking and floating of an object is the weight of an object, the volume of liquid, and the mass of the object. Another common misconception found in this study is when the students think that the heavy objects will sink in water, and light objects will float on water. Some of the students also have misconceptions on the density of the floating objects is greater than the density of the sinking objects. This is explained in the study by [23] that shows the misconception in buoyancy-related phenomena is related to the concept of density.

Most of the students knew that the buoyancy concept was the concept related to the activity and majority of the students can be classified to have high and moderate level of concept understanding. This finding is assumed due to the students' familiarity of the informal learning that may have been introduced in the formal learning. In contrast, when students were not able to make any inference based on the observations, the self-determination skill surfaced because they were required to make a decision and plan for the design.

Referring back on the need for innovation in informal science learning, this study took an initiative to develop a module targeting at technology application. In formal 
setting, this often been introduced as an example of application or as project based activity. Constraint in formal setting however often drive students from their original ideas and enact on that ideas for better understanding. The informal science learning has variety of ways to make the students interested to learn science and at the same time provide a more democratic choice for ways of knowing. This study showed that when informal science activity is carefully designed, students are given the opportunity to develop values for observations and inferences. The activity also drives students' self-determination during learning.

\subsection{Managing Knowledge Ownership during Informal Science Activities}

However, conducting informal science learning come with a challenge which is time management. Since this activity is a part of Explorace type of camp, students did not realize that the activity is meant for them to learn. The students did not give their full attention to the subscribed knowledge that they must presented to complete the activity. However, due to the feeling of competitive "to finish first" rather students aimed to produce the best result regardless of the final outcome of the learning. This is aligned with the failure of the STEM activities discovered in current STEM education [24], [25]. Based on the observations, there were some of them that did not pay attention to the conversations with their group members.

In this study however, the activities were carefully design into several stages that require students to acknowledge their decision making and the impact of that decision. This has created sense of urgency for students to properly determine the variables in the activity. The facilitators play the biggest role to ensure that students are put into a situation that require them to think, and give a "passport chop" as an evidence for completing that stage.

\section{Conclusions}

The designing and testing the boat to test initial assumptions are the episode which have gained students' interest. The experience gained during the deconstruction, construction and reconstruction of knowledge. This study shows that informal science learning is a valuable tool to help students readjust and reevaluate their prior knowledge. The sequence of activities has allowed the students to take appropriate actions to formulate and solve problems in an unfamiliar setting. Moreover, it can be concluded that a properly planned informal learning environment will able to create opportunity for students to learn and it will create opportunities for teachers to with technology application in physics lessons. 
Paper-Informal Science Pedagogical Innovation to Promote Understanding of Technology...

\section{$7 \quad$ Acknowledgement}

This project is funded under Fundamental Research Grant Scheme (FRGS) FRGS/1/2018/SSI09/UTM/02/5 by The Ministry of Education Malaysia with vote number R.J130000.7853.5f067.

\section{$8 \quad$ References}

[1] L.D. Dierking, J.H. Falk, L. Rennie, D. Anderson, and K. Ellenbogen, "Policy statement of the "Informal Science Education" Ad Hoc Committee," Journal of Research in Science Teaching, vol 40, pp. 108-111, 2003. https://doi.org/10.1002/tea.10066

[2] J. Minogue, and D. Borland, "Investigating students' ideas about buoyancy and the influence of haptic feedback," Journal of Science Educational Technology, vol 25, pp. 187-202, 2016. https://doi.org/10.1007/s10956-015-9585-1

[3] G.T. Prins, A.M.W. Bulte, and A. Pilot, "An activity-based instructional framework for transforming authentic modelling practices into meaningful contexts for learning in science education," Science Education, vol 100, no 6, pp. 1092-1123, 2016. https://doi.org/ $\underline{10.1002 / \text { sce. } 21247}$

[4] M. J. Reiss, B. Billingsley, E. M. Evans, R. A. Kissel, M. Lawrence, T. Mujtaba, and D. Veall, The contribution of natural history museums to science education. London: UCL Institute of Education, 2016, pp1-88.

[5] M. Çevik, "Impacts of the project based (PBL) science, technology, engineering and mathematics (STEM) education on academic achievement and career interests of vocational high school students," Pegem Eğitim ve Öğretim Dergisi, vol 8, no 2,pp. 281306, 2018. https://doi.org/10.14527/pegegog.2018.012

[6] D. H. Allsopp, M. M. Kyger, \& L. H. Lovin, Teaching mathematics meaningfully: solutions for reaching struggling learners. Baltimore: Paul H. Brooke Publishing Co., Inc, 2007, pp. 1-14.

[7] J.S. Brown, A. Collins, and P. Duguid, "Situated cognition and the culture of learning," Educational researcher,vol 18, no1, pp. 32-42, 1989. https://doi.org/10.3102/0013189x $\underline{018001032}$

[8] O. G. Stewart, and M. E. Jordan, "Some explanation here: A case study of learning opportunities and tensions in an informal science learning environment," Instructional Science, vol 45, pp. 137-156, 2016. https://doi.org/10.1007/s11251-016-9396-7

[9] J.A. Holmes, "Informal learning: Student achievement and motivation in science through museum-based learning," Learning Environment Research, vol 14, pp. 263-277, 2011. https://doi.org/10.1007/s10984-011-9094-y

[10] C. Julià, and J.O. Antolí, "Spatial ability learning through educational robotics," International Journal of Technology and Design Education, vol 26, no 2, 2015

[11] S. Stocklmayer, L. Rennie, and J. Gilbert, "The roles of the formal and informal sector in the provision of effective science education," Studies in Science Education, vol 46, no 1, pp. 1-44, (2010). https://doi.org/10.1080/03057260903562284

[12] National Research Council (NRC). Learning science in informal environments: People,places, and pursuits. Washington, DC: The National Academies Press, (2009).

[13] T.Roberts, C. Jackson, M.J. Mohr-Schroeder, S.B. Bush, C. Maiorca, M. Cavalcanti, D.C. Schroeder, A. Delaney, L. Putnam, and C. Cremeans, "Students' perceptions of STEM learning after participating in a summer informal learning experience," International 
Paper-Informal Science Pedagogical Innovation to Promote Understanding of Technology...

Journal of STEM Education, vol 5, no 35, 2018. https://doi.org/10.1186/s40594-018-0133$\underline{4}$

[14] J.S. Brown, A. Collins, and P. Duguid, "Situated cognition and the culture of learning," Educational researcher,vol 18, no1, pp. 32-42, 1989. https://doi.org/10.3102/00131 $\underline{89 \times 018001032}$

[15] E.E.P. Burton, and S.E. Hiller, "Fun Science: The Use of Variable Manipulation to Avoid Content Instruction," Journal of Science Teacher Education, vol 24, pp.199-217, 2013. https://doi.org/10.1007/s10972-012-9269-0

[16] M/G. Khanaposhtani, C.J. Liu, B.L. Gottesman, D. Shepardson, and B. Pijanowski, "Evidence that an informal environmental summer camp can contribute to the construction of the conceptual understanding and situational interest of STEM in middle-school youth," International Journal of ScienceEducation, pp.1-22, 2018. https://doi.org/10.1080/21548 $\underline{455.2018 .1451665}$

[17] G.T. Prins, A.M.W. Bulte, and A. Pilot, "An activity-based instructional framework for transforming authentic modelling practices into meaningful contexts for learning in science education," Science Education, vol 100, no 6, pp. 1092-1123, 2016. https://doi.org/ $\underline{10.1002 / \text { sce. } 21247}$

[18] S.M. Stehle, and E.E.P. Burton, "Developing student $21^{\text {st }}$ century skills in selected exemplary inclusive STEM high schools," International Journal of STEM Education, vol 6, no 39, pp. 1-15, 2019. https://doi.org/10.1186/s40594-019-0192-1

[19] H. R. Bernard, Research methods in anthropology: Qualitative and quantitative approaches (3rd ed.). Walnut Creek, CA: Alta Mira Press, 2002.

[20] D. B. Larkins, J. C. Moore, L. J. Rubbo, and L. R. Covington (2013). "Application of the Cognitive apprenticeship framework to a middle school robotics camp. In ) (Ed.)," Proceeding of the 44th ACM technical symposium on Computer science education, pp. 89-94, (2013). https://doi.org/10.1145/2445196.2445226.

[21] B. Rohrig, "Making a Mini-Submarine,"Science Teacher, vol 68, no 2, pp. 38-41, 2001.

[22] O. Zajkov, S.G. Zajkova, and B. Mitrevski, "Textbook-caused misconceptions, inconsistencies, and experimental safety risks of a grade 8 Physics textbook," International Journal of Science and Mathematics Education, 837-852, 2017. L.D. Dierking, J.H. Falk, L. Rennie, D. Anderson, and K. Ellenbogen, "Policy statement of the "Informal Science Education" Ad Hoc Committee," Journal of Research in Science Teaching, vol 40, pp. 108-111, 2003. https://doi.org/10.1007/s10763-016-9715-0

[23] B. Rohrig, "Making a Mini-Submarine,"Science Teacher, vol 68, no 2,pp. 38-41, 2001.

[24] J. Banks, K. Au, A. Ball, P. Bell, E. Gordon, K. Gutierrez et al. Learning and out of school in diverseenvironments: Life-long, life-wide, life-deep. Washington, DC: The LIFE Center, 2007.

[25] M. Çevik, "Impacts of the project based (PBL) science, technology, engineering and mathematics (STEM) education on academic achievement and career interests of vocational high school students," Pegem Eğitim ve Öğretim Dergisi, vol 8, no 2, pp. 281306, 2018. https://doi.org/10.14527/pegegog.2018.012

[26] A. T., Jones, \& C. M. Kirk, (1989). "Teaching technological applications in the physics classroom". Research in Science Education, 19(1), 164-173.

[27] N. K. Ruzaman \& D. I. Rosli (2020). "Inquiry-Based Education: Innovation in Participatory Inquiry Paradigm.” International Journal of Emerging Technologies in Learning (iJET), 15(10), 4-15. https://doi.org/10.3991/ijet.v15i10.11460.

[28] N. Nehiri, \& N. Aknin (2021). "A Proposed Learner's Data Model: Integrating Informal Learning and Enhancing Personalization and Interoperability." International Journal of 
Paper-Informal Science Pedagogical Innovation to Promote Understanding of Technology...

Emerging Technologies in Learning (iJET), 16(8). https://doi.org/10.3991/ijet.v16i08. $\underline{19833}$

[29] S. Riaz, D. R. Rambli, R. Salleh \& A. Mushtaq (2010). Study to investigate learning motivation factors within formal and informal learning environments and their influence upon web-based learning. International Journal of Emerging Technologies in Learning (iJET), 5(4), 41-50. https://doi.org/10.3991/ijet.v5i4.1338

\section{Authors}

Nor Farahwahidah Abdul Rahman is an expert in social science studies at the School of Education, Faculty of Social Sciences and Humanities, Universiti Teknologi Malaysia (UTM), 81310 Skudai, Johor, Malaysia. She received her B.Sc (Physics education), Master of Philosophy (Physics Education) and $\mathrm{PhD}$ from Universiti Teknologi Malaysia. Her research interest is mainly on the social aspect and impact on STEM education and education in general.

Anis Nadirah Roslan is a first year PhD student at the School of Education, Faculty of Social Sciences and Humanities, Universiti Teknologi Malaysia (UTM), 81310 Skudai, Johor, Malaysia specializing in inquiry based learning in Physics.

Alya Nazirah Azaha is a graduate student in Master of Education (Physics) from the School of Education, Faculty of Social Sciences and Humanities, Universiti Teknologi Malaysia (UTM), 81310 Skudai, Johor, Malaysia.

Nadharatul Hidaayah Ismail is a graduate student in Master of Education (Physics) from the School of Education, Faculty of Social Sciences and Humanities, Universiti Teknologi Malaysia (UTM), 81310 Skudai, Johor, Malaysia.

Mazlena Murshed is a PhD student at the School of Education, Faculty of Social Sciences and Humanities, Universiti Teknologi Malaysia (UTM), 81310 Skudai, Johor, Malaysia specializing in multi-representative in physics.

Article submitted 2021-06-26. Resubmitted 2021-07-27. Final acceptance 2021-07-27. Final version published as submitted by the authors. 